multidisciplinary teams does not expect to answer all questions which such teams face in operation. It cannot take into account the idiosyncracies of real teams. All it purports to do is to present a taskbased framework and point to the resulting boundaries and limits. In doing so, it risks dissatisfying almost everybody, since the acceptance of boundaries is generally emotionally unwelcome, yet notions of omnipotence or omniscience have little place in professional reality. On these last two words the case rests.

\section{References}

CheCKLAND, P. B. (1971) A systems map of the Universe. Journal of Systems Engineering, 2(2).

INTERDISCIPLINARY STANDING COMMITTEE (1981) Interdisciplinary Work in Child Guidance. The Child Guidance Trust.

OVERTWeIt, J. (1986) Case Responsibility in MultiDisciplinary Teams (BIOSS)

Rowbotтoм, R. \& HeY, A. (1978) Organisation of Service for the Mentally IIl, Working Paper, Brunel Institute of Organisational and Social Studies (BIOSS).

\title{
NHS indemnity for medical negligence: its implications
}

\author{
Ram SETH, Senior Registrar, The Bethlem Royal Hospital, Beckenham, Kent BR3 3BX
}

From 1 January 1990 medical and dental practitioners employed by health authorities were no longer required under the terms of their contracts to subscribe to a medical defence organisation. The health department, however, advised practitioners (DHSS circular) to "maintain their defence body membership in order to ensure they are covered for any work which does not fall within the scope of the indemnity scheme". The expediency with which the scheme was introduced enabled little discussion on the consequences of such change and surprised medical practitioners and defence organisations alike. This major change in medical indemnity since 1954 will have long-term implications for practitioners, medical defence organisations, local health authorities and most importantly, the quality and quantity of health care which can be delivered. A meeting held on 9 April 1990 at Charter Nightingale Hospital was convened to discuss the implications of the NHS indemnity scheme between senior registrars in psychiatry and representatives from the Medical Defence Union, Medical Protection Society, British Medical Association and the local health authority.

\section{Why the change?}

From 1954 until 1 January 1990, health authorities have had a vicarious relationship with their prac- titioners concerning medical defence (HM 54 32). The last 10 to 15 years have seen steeply rising subscription premiums to defence organisations, resulting in the introduction of competitive and differential premiums. The effect of such changes on recruitment to various medical specialties was buffered by the introduction of two-thirds reimbursement of defence body fees by the health authorities in 1989. However, within a year of this change the health secretary, with great expediency, introduced the NHS indemnity scheme from 1 January 1990, with most practitioners receiving notification of this change in November/December 1989. Limited negotiations had taken place between the health department and the defence organisations and it was clear from this meeting that they were critical of such a scheme being able effectively to deal with the rapidly rising claims for medical negligence. Of much more concern were the effects of such a scheme on the finances of local health authorities and the necessarily altered relationship with their practitioners. All representatives were in agreement that practitioners should continue with a basic medical subscription. Medical work not covered by the NHS indemnity includes any private work, good samaritan work, locum sessions in general practice and any legal work such as prison visits, solicitors' reports and 
mental health act work not contracted by the health authority.

The health authority is responsible for settlements, awards, legal and administrative cost for all contractual work leading to defence cases. Health authorities have $£ 100,000$ designated to meet such costs. They did, however, have $£ 141,000$ in provision for reimbursing two-thirds of the defence organisation fees when these were in operation. This analysis is incorrect in the assumption that reimbursement was equal to indemnifying costs. The aim of the health authorities is therefore to introduce policies to minimise risk of medical negligence by advocating better practice of incident recording, and appraisal, improvements in case note recording, to emulate higher standards of clinical practice and to maintain the impetus of clinical audits. The health authorities now have a dual role as the employer and the insurer and may find it difficult to distinguish between disciplining and defending their members. The LHA are not permitted to insure themselves, invest or hold reserves which the defence organisations were privileged to have. With the limited revenue available for indemnifying its members the tendency will be to settle cases out of expediency and not on merit or in the interests of the medical practitioner. The LHA were unaware of the indemnity scheme in its planning stages and at present are not in a position to quantify the extra financial burden which they will have to meet out of existing finances. The added problem in calculating such costing is that a number of LHAs treat patients out of their districts and the unresolved question as to whether the local authorities would incur the costs.

\section{What does it mean for defence organisations?}

The MPS received more enquiries from psychiatrists than any other medical specialties in the previous year. Before January $1990,10 \%$ of the work of the defence organisations was in dealing with claims and the rest was advisory. For practitioners opting not to have basic defence body cover this service will no longer be available to them under the NHS indemnity scheme. The major burden of legal costs for medical negligence of the defence organisations went to cases of brain damage with the introduction of brain damage research risk management directives from Donald Acheson. A transfer of $£ 300,000$ has been made to the defence organisations for settlement of cases initiated before January 1990 for which the LHA also takes full responsibility. The fate of the defence organisations is not yet clear as to whether the LHA will contract out their services or develop their own. The latter option will clearly mean a loss of considerable expertise which the defence bodies have acquired over the years. There was clearly apprehension concerning no fault compensations being made by LHA and thus offering no protection for doctors' reputations, e.g. the recent case of Dr Ludwick would have been dealt with differently.

\section{Comment}

Although NHS indemnity offers medical practitioners relief from paying the rising defence body subscriptions, the change will clearly mean an extra cost for the LHA from their existing budgets. With the likelihood of record settlements continuing to be awarded by courts for the plaintiff, the LHA will necessarily have to make cuts in their services which will have a direct effect on the quality and quantity of health care which can be offered. Without additional funding for indemnity by the health secretary, it will certainly mean another nail in the coffin of the ailing NHS. 